\title{
Spatio-temporal simulation of the geopolitical environment system
}

\author{
GE Quansheng ${ }^{1,2}$, "JIANG Dong ${ }^{1,2,3}$, LU Feng ${ }^{1,2}$, FU Jingying ${ }^{1,2}$, \\ WANG Shaoqiang ${ }^{1,2}$, DENG Xiangzheng ${ }^{1,2}$
}

1. Institute of Geographic Sciences and Natural Resources Research, CAS, Beijing 100101, China;

2. College of Resource and Environment, University of Chinese Academy of Sciences, Beijing 100049, China;

3. Key Laboratory of Carrying Capacity Assessment for Resource and Environment, Ministry of Land \& Resource, Beijing 100038, China

\begin{abstract}
Geographical circumstances are the fundamental background for all kinds of geopolitical events. The geopolitical environment system (GES) refers to a system that combines both physical and anthropogenic subsystems. Research on the geopolitical environment system simulation is a key to understanding the international geopolitical phenomenon. The theory of GES arose from the integration of the traditional geopolitics and earth system sciences. As an interdisciplinary system composed of many different fields, integrated reviews and a metadata study of GES are urgently needed. This paper presents a comprehensive view into the origination and advance of the GES theory. The conceptual framework of the GES is described in detail. The methodology for simulating and forecasting geopolitical events is also provided. It is proposed that the core topics of the GES science may include, but are not limited to, issues as data acquisition technologies; principles on the interactions between multiple subsystems (or factors) at different scales; evaluating and mitigating the global geopolitical risks, including the political risks, economic risks, the social risks, the environmental risks and the technological risks; and forecasting the geopolitical events with machine learning and artificial intelligence techniques.
\end{abstract}

Keywords: geopolitical environment system; geopolitical conflicts; risk mitigation; big data analysis

\section{Introduction}

Geographical settings are the basis of all kinds of political actions. As demonstrated one hundred years ago by H. J. Mackinder, the actual balance of political power at any given time is the product of geographical, economic and strategic conditions (Mackinder, 1904). The term geopolitical environment refers to the combination of natural and social environments. A geopolitical environment system (GES) is a gigantic and complex system that consists of physical elements (topography, geomorphology, water and land resources, meteoro-

Received: 2017-08-26 Accepted: 2017-10-21

Foundation: Major Program of Chinese Academy of Sciences, No.ZDRW-ZS-2016-6

Author: Ge Quansheng (1963-), Professor, specialized in climate change and geopolitical system. E-mail: geqs@igsnrr.ac.cn

*Corresponding author: Jiang Dong, Professor, E-mail: jiangd@igsnrr.ac.cn 
logical conditions, etc.) and socio-economic elements (demography, society, ethnicity, culture, politics, etc.) (Ge et al., 2017). The theory of GES arose from the integration of the traditional geopolitics and earth system sciences. Political geography is concerned with the study of the inter-relationships between people, state, and territory (Painter, 1995). "Geopolitics", a branch of 'political geography', is a method of studying foreign policy to understand, explain and predict international political behavior through geographical variables (Evans and Newnham, 1998). It is common sense that the origination and development of regional/global political or economic patterns were influenced by geographical factors (Erickson et al., 2014). In 1899, Rudolf Kjellén first mentioned the term 'geopolitics' and defined it as a theory of looking at the state as a geographic organ or spatial phenomena (Cohen, 2014). The development of GES theory, which was affected by the conditions of the productivity, science and technology of a certain era, might be divided into three stages: the classical geopolitics before the World War II, geopolitics in the Cold War period, and geopolitics in the post-Cold War period ( $\mathrm{Lu}$ and Du, 2013; Kong, 2010).

Power and control of the nation are the main concern of the classical GP. The expansion of the nation was controlled by the power of the nation which was affected by the geographical issues, such as location and distance. The 'power' varied among different eras, according to the productivity of that era. Theories on the organic characters of the states, such as 'Land Power Theory' (Chen, 2009), 'Sea Power Theory' (Mahan, 2006), 'Airpower Theory' (Seversky, 1950), have successively appeared. From this point of view, the world could be divided into a central region (the Eurasian continent) and a marginal area. In 1904, H. J. Mackinder presented the 'Heartland Theory' in his paper, 'The Geographical Pivot of History' (Mackinder, 1904). He suggested that the control of Eastern Europe was vital to the control of the world. N. J. Spykman proposed the Rimland Theory in 1942 and thought that the 'Rimland' was more important than the 'Heartland' (Central Asia) for the control of the Eurasian region (Spykman, 1965). The dominating political ideology is the confrontation between the West and the East for the geopolitics during the Cold War period. The world was divided into two geopolitical regions: the West and the East. It was suggested that the geopolitical strategy on each conflict point should be analyzed under the global view (Kissinger, 2012), the transitional zones (Spykman, 1965) and the key zones (Brzezinski, 2012). The concept of 'power' of the nation has changed with the ecological globalization and the revision of the global geopolitical patterns after the Cold War. The theory of geopolitics became richer and balanced, meanwhile, the 'Central Empire' and 'Two Poles' have been replaced by the multiple polar geopolitical entities. The means of a geopolitical relationship changed from confrontation to multiple types of competition and mutualistic symbiosis (Mao, 2013). Studies on geo-economics and geopolitical civilization have caught the public's attention.

In addition to economic globalization, a series of global problems about resources and the environment resulting from global warming, ozone depletion and population pressures, etc., exceeded the boundary of a single discipline. Treating the Earth as an integrated system, Earth system science (ESS) is about the interactions of the lithosphere, hydrosphere, biosphere and atmosphere, as well as the impact of human societies on these components. ESS studies the Earth system at multiple scales and from a systematic point of view that helps us to achieve a better understanding of the nature of what we depend on for our survival (Zheng 
and Chen, 2001). The global change researches aimed to explore the dynamics of climate change and its impacts on physical environment as well as social society worldwide (Ma et al., 2014). Regulated by the global integrated research program, such as Global Environment Outlook (UNEP, 2017) and 'Future Earth' (Future Earth, 2017), Earth observation techniques (data mining, machine learning, big data analysis, etc.) have been adopted in a transcending, disciplinary boundaries approach. This approach promotes the GES study from being a single element or regional study to an integrated simulation of multiple elements at multiple scales.

Globalization will not terminate the influence of the geographic factors. Instead, it will cause a much more complicated geopolitical system (Xin, 2016). In the new millennia, it was found that stable societies were becoming fragmented in many regions of the world (WEF, 2017). Regional geopolitical risks may cause significant effects worldwide (Ge et al., 2007). Simulating the GES, the assessment of the risk and forecasting geopolitical events by combining physical and social sciences has attracted much attention in recent years. The concern of this paper is to present a comprehensive review of the progress of the theory and methodology in the geopolitical environment system, to introduce the state-of-the-art approaches to geopolitical events modeling and to provide an in-depth perspective of the prospect of GES science.

\section{Theoretical basis for the geopolitical environment system}

\subsection{Conceptual framework of the geopolitical environment system}

Saul Cohen studied the dramatic geopolitical changes since the 1990s in the context of the physical and social settings (Cohen, 2014). It has been expected since the end of the 19th century that the formula that applies equally to history and to present politics will be discovered (Mackinder, 1904). According to the general systems theory, a geopolitical system is a collection of interdependent parts enclosed within a defined boundary. Consequently, a GES is made up of three components: geopolitical actors (agents), relationships among these agents and the geographical environment (formula 1) (Bertalanffy, 1972).

$$
S=f(N, R, G)
$$

where $S$ equals the GES, and $N$ stands for the geopolitical operators. The nation is a typical type of geopolitical agent. International, political or economic organizations, together with the sub-regions within nations, could also be considered as geopolitical agents. $R$ is the relationship among different geopolitical agents. $G$ stands for all outside environments in which the geopolitical agents exist. $G$ consists of not only the physical environment but also socio-economic environments, including topographical, meteorological, natural resources, political, social, economic, and cultural elements (Ge et al., 2017).

One of the fundamental characters of the GES is that it has multiple scales. A GES is composed of some geopolitical elements (subsystems), and each subsystem itself may be composed of several little subsystems as well (Bertalanffy, 1972). The principles and dynamics of the GES vary at different scales. For example, Koen presented a multiple-level world model, which suggested that a GES could be divided into the geopolitical jurisdiction, geopolitical zones and nations (Cohen, 2014). The International Institute for Applied Systems Analysis (IIASA) divided the world into five regions for global energy security as- 
sessment: Organization for economic cooperation and development (OECD90); Eastern Europe and Russia (REF); Asia (except for OECD90 countries, ASIA); the Middle East and Africa (MAF); and Latin America and Caribbean countries (LAC) (GEA, 2012). The GES at each scale is controlled by several key factors, including physical and socio-economic factors. The research of GES relies on the integration of natural science and the humanities and should focus on the interdisciplinary theories and methodologies.

A system is an organic entity, and its function is the output of the interaction of all kinds of inner factors. The GES could be described with n factors (state variables, $Q_{i}, i=1-n$ ) from three categories $(N, R, G)$ mentioned in formula 1 . The variation of each variable $Q_{i}$ is the function of all indices. The dynamic of the system can be described with a group of first-order differential equations (formula 2) (Bertalanffy, 1972):

$$
\frac{d Q_{i}}{d t}=f_{i}\left(Q_{1}, Q_{2}, \cdots, Q_{n}\right)
$$

where $Q_{i}$ stands for the $i$ th state variable of a GES. The transformation of the GES may be described as the trajectory of the state variables in the $n$ dimension state space (Bertalanffy, 1987). Assuming that a GES stays stable over time, formula 2 is equal to zero. Then, a series of initial values of the state variables can be achieved.

In fact, it is difficult to achieve a resolution from formula 2. For GES simulation, numerical analysis methods might be adopted to obtain an approximate resolution with a rational assumption and simplification of the geopolitical relationship and the boundary of the system.

\subsection{Modeling the dynamic of the GES}

It is not applicable to directly use conventional modeling methods for GES simulation. The high dimension complicates relevance and produces multiple objectives of the GES. Studies suggest that the concepts of multiple representation modeling and large-scale system decomposition could be adopted, according to the system theory and contemporary control theory. J. David Singer created a statistical index, the Composite Index of National Capability (CINC), for evaluating national power (Kim, 2010). The CINC score, which takes into account both military factors and economic and cultural factors for national power evaluation has been widely used in recent studies.

Ari Litwin and Jimmy Allen Davis designed a conceptual structure of a geopolitical information system, which combined multiple geopolitical indices with a geographic information system (GIS). Mazis presented a theoretical paradigm of Systemic Geopolitical Analysis. A geopolitical system might be divided into four key elements: military, economy, politics, and information (Mazis, 2014). Therefore, Nicholas J. Daras gave two common models to predict geopolitical incidents in a certain GES (Daras and Mazis, 2015). Beatriz Munoz focused on the energy security within certain geopolitical environments. The GES was simplified as an energy agent (the producing, transit and consuming countries), energy relationship, and geographical environment (energy supply corridors, etc.). Thirteen indices from four categories (economic, energy specific, social political and EU relations) were selected. A composite geopolitical energy supply risk index (GESRI) was computed for 122 countries based on those indices (Muñoz et al., 2015). The Global Risk Report (GRR) by the World Economic Forum defined global risk as an uncertain event or condition that can cause 
significant negative impacts on regional or national groups within the next decade. Twentynine global risks were defined and classified into five categories: economic, environmental, geopolitical, societal and technological (WEF, 2017).

In general, a large, complicated GES could be decomposed into three scales, i.e., macroscopic scale (global), mesoscopic scale (national) and microscopic scale (local). A universal model may be composited from the integration of multiple models at different scales (Hirsch et al., 2008). The steps are as follows:

1) Determine the study area and boundary of the system;

2) Identify the key geopolitical environment elements;

3) Progressively analyze the variation of the key geopolitical elements during certain geopolitical events;

4) Explore the mechanism of the interaction among multiple key elements and determine the triggering points of forcing factors.

\section{Global network for geopolitical environment monitoring}

\subsection{Observation systems for natural and social circumstance}

Qualified and timely data are critical to the geopolitical environment system research. To understand the geographical relationship scientifically, comprehensive analysis and deep mining of scientific data with relatively complete time series data are necessary. A geographical-based, in situ observation network has been established for natural ingredients monitoring. Those networks include the Global Climate Observation System (GCOS) and a global network of micrometeorological tower sites (Fluxnet), etc. (Qin, 2014). Various comprehensive global plans have also been performed aiming at the study goals from the different angles and discipline backgrounds and have provided plenty of the datasets of the Earth System (energy and water cycle, climate and cryosphere, land use cover, atmosphere, oceans, human security and biodiversity, etc.) on a global scale for the geopolitical system research.

With the development of remote sensing, geo-information and computer technology, there are various global and regional spatial data of population-based, on-land use and nighttime lighting: Gridded Population of the World (GPW), LandScan population data of Oak Ridge Laboratory with the resolution of 30 seconds, AfriPOP, AsiaPop, AmeriPop in the Global Information Database of the United Nations Environment Program (http://www.clas. ufl.edu/), and the global GDP spatial distribution dataset G-Econ built by the Yale University in the United States with the observation data of 27,500 administrative units worldwide (http://gecon.yale.edu/). The World Bank (WB) developed the urbanization datasets for different countries of the world for the period from 1960 to 2014. (http://issuu.com/world. bank.publications/docs/9781464803635_465fe137eeee15).

\subsection{Geopolitical incidents recording and monitoring}

Many important changes in natural systems and human socio-economic systems often appear suddenly and unexpectedly. These were defined as unexpected geopolitical events, including natural disasters, accident catastrophes, public health incidents and social security incidents. Recording and monitoring such events are of vital importance to the GES study. 
Extreme weather events and natural disasters occur more frequently, and their intensity and impact continue to increase. The increasing trend of weather disasters (storms), hydrological disasters (floods, debris flows, and landslides) and climate disasters (extreme temperatures, droughts, and forest fires) will cause the instability of societies and potentially cause riots, insurgencies, urban violence, or war. The research of rapid monitoring and evaluating disaster events have been performed for a long time. As a case in point, the Disaster Risk Index (DRI) presented by the United Nations Development Program (UNDP) is the representative of natural disaster risk management. On the national scale, HAZUS is widely used in the United States. In addition, on the local and community scales, there is CBDRM (Community based disaster risk management) in Asia and CDM (Community disaster management) in Europe (http://www.grid.unep.ch/activities/earlywarning/DRI/).

Conflicts triggered by disasters, terrorism, regional conflicts and ethnic conflicts will cause a significant impact on geopolitical relations and affect the security of resources and energy. Because of this, all kinds of conflicts should be monitored in time and space. For this purpose, some programs have been conducted, such as the Centre for the Study of Civil War data (CSCW)(https://www.prio.org/Data/ Datasets/), the Uppsala Conflict Data Program (UCDP) Dataset (http:// www.pcr.uu.se/research/ucdp/dataset $\mathrm{s} /$ ), the Armed Conflict Location and Events Dataset (ACLED) (http:// www.acleddata.com/) and the Global Terrorism Database (GTD) (http:// www.start.umd.edu/gtd/). The variation of global geopolitical conflicts can be derived from those datasets (Figure 1).

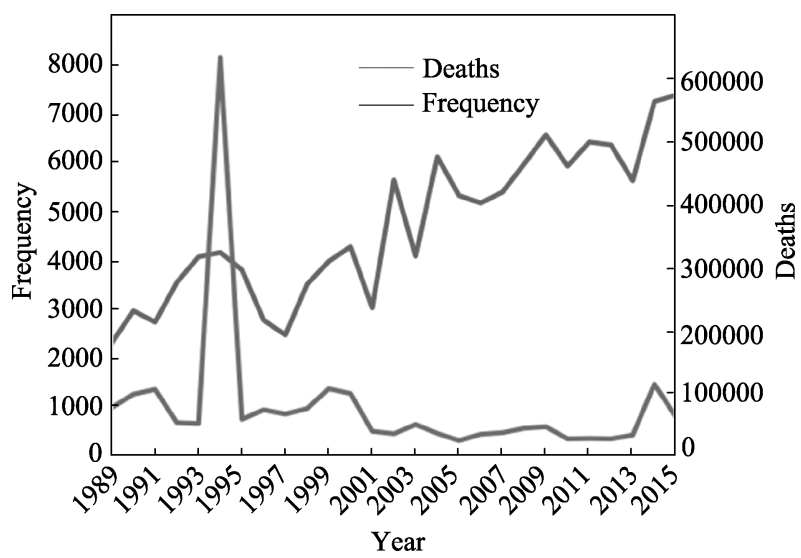

Figure 1 The number and frequency of injured persons caused by armed conflicts worldwide (1989-2015)

\section{Methods for geopolitical events simulating and forecasting}

\subsection{Identifying the characteristics of the GES actors}

The characteristics of GES operators, countries and international organizations, may significantly influence the progress of the GES. Alesina et al. (2010) suggested that the size of a nation was determined by the trade-off between scale economies and the costs of population heterogeneity that favor smaller countries. Klaus Desmet et al. (2011) quantitatively explored the breakup of nations in the EU region. The nations were characterized as a set, which consisted of multiple regions with cultural or economic heterogeneity. They used cultural distance and income distance as the main driving forces and found that 'economic differences' determined the order of disintegration and 'cultural differences' were the keys to the national instability (Miller, 2016). Recent studies revealed that a terrorist activity could be conceptualized as a social network and, in turn, a terrorist network. Simulation of a terrorist-organization structure may help to understand its properties and characteristic ac- 
tions (Joshua, 2012). Kiruthiga et al. (2015) described the hub-spoke terrorist organization structure with a graphical, computer-aided, experimental modeling method. Clauset and Gleditsch (2012) identified the principle of terrorist attacks. They found that the influences of violent events tended to accelerate with increased size and experience. To address the patterns of the Islamic State of Iraq and Levant (ISIL) related to terrorism, a recently published report from START classified the terrorist attacks into four ISIL-related perpetrator categories: ISIL predecessor, ISIL, ISIL affiliate and ISIL-inspired. The report illustrated the variations of ISIL-related terrorism over time and space (Miller, 2016).

In recent years, agent-based models have been widely adopted to simulate actions of nations in the world. Cederman et al. (2012) established the GeoSim, which is a model family which can well explain geopolitical phenomena. Weidmann and Girardin (2006) presented a software toolbox GROWLab (Geographic Research on War Laboratory), which provides a set of tools to support GES research.

\subsection{Simulating and forecasting the geopolitical events}

Quite a few previous studies indicated that geopolitical events occurred in non-random ways (White et al., 2013). A special section was published in Science in early 2017 for discussing the prediction and its limits. Ryan Kennedy et al. (2017) believed that with the aid of new techniques and data sources, elections and other geopolitical events will be predictable. Jasny and Stone (2017) developed prediction models using a dataset covering 86 nations and more than 500 elections. The results indicated that their method could predict $80 \%$ to $90 \%$ of elections in out-of-sample tests.

Climate variability has been considered to have a close relationship with armed conflict. Nina von Uexkull assessed the relationship between civil conflict and growing-season drought. They found that for agriculturally dependent groups and politically excluded groups in poverty-stricken nations, a local drought is found to increase the risk of social violence (Von et al., 2016). Hsiang et al. (2013) quantified the impacts of climate on the social conflict. The results indicated that variation of precipitation and temperature systematically increased the probability of local conflict.

Literatures on the characters of conflicts and their relation to socio-economic conditions increased quickly in recent years. Economic elements, such as oil scarcity, may become the driving forces for geopolitical violence (Cotet and Tsui, 2013; Schneider and Troeger, 2011). Funke et al. (2015) studied the political fall-out from systemic financial crises over the past 140 years based on a long time series dataset of about 800 elections. The result indicated that far-right parties increased their vote share by $30 \%$ after a financial crisis; José Noguera-Santaella (2016) conducted a time series analysis to examine the influences of 32 geopolitical incidents on real oil prices from the American Civil War (1859) to the Arab Spring episodes (2011). The results suggested that geopolitical incidents influenced oil prices positively before 2000 but had little impact afterward.

In 2013, Mayer-Schonberger and Cukier (2013) noted that the development of big data will have a dramatic impact on the economy, science, and society as a whole. Big data analysis based on intensive data has become the fourth paradigm of scientific research. In addition to mathematic modeling, the big data method has proven to be an efficient alternative approach for GES simulation (Fernández-Delgado et al., 2014). Based on the dataset 
from the GTD, White et al. (2013) presented an empirical method for exploring terrorist activity from 2000 to 2010 in three Southeast Asian countries including Indonesia, the Philippines and Thailand. One of the main shackles of big data based modeling is identifying valuable information from noise (Jasny and Stone, 2017). Machine learning is good at handling enormous numbers of predictors and combining them in a nonlinear and highly interactive way (Athey, 2017). Data mining and machine learning methods, which take into account both physical and socio-economic datasets, have proven to be more efficient for forecasting geopolitical incidents. Gao et al. (2013) presented a data-mining approach for modeling geopolitical incidents. This method used prospective space-time scan statistics and could detect outbreaks of terrorist events at an early stage. Ding et al. (2017) demonstrated a deep learning method to evaluate risks of terrorist attacks on a global scale based on GTD dataset and other multiple resources datasets. The method performed well in predicting the terrorism incidents with a precision of $96.6 \%$.

\section{Conclusions}

It has been more than a century since the origination of the concepts of geopolitics and political geography. Today, the theory of GES, which pays much attention to the integration and interdisciplinary study, has developed rapidly. According to the demands of application and the new advance in GEP and related techniques, the core topics of GES science may include issues as follows:

(1) Data acquisition technologies. It is necessary to establish a seamless observation system for geopolitical elements by combining multiple data acquisition approaches. Geographical Information System (GIS), along with remote sensing and other spatial information techniques, will play an important role for geopolitical data management, data mining and data visualization.

(2) Principles of the interactions between multiple subsystems (or factors) at different scales. These principles not only include the interactions between the five Earth spheres but also the global flows of people, resources and information.

(3) Evaluating and mitigating the global geopolitical risks, including the political, economic, social, environmental and technological risks.

(4) Forecasting the geopolitical events with machine learning and artificial intelligence techniques. The existing physical models, such as the land surface model, climate model and ocean model, should be coupled at regional and global scales. Additionally, the socio-economic models, including international trade, urban development, etc., should also be simulated.

With the progress of related science and technologies, the aforementioned techniques will play significant roles in geopolitical system research.

\section{References}

Alesina A, Easterly W, Matuszeski J, 2010. Artificial states. Journal of the European Economic Association, 9(2): $246-277$.

Athey S, 2017. Beyond prediction: Using big data for policy problems. Science, 355: 483-485.

Bertalanffy L V, 1972. The history and status of general systems theory. The Academy of Management Journal, 15(4): 407-426. 
Bertalanffy L V, 1987. The History and Status of General Systems Theory. Beijing: Tsinghua University Press.

Brzezinski Z, 2012. Big Chess: U.S. Primacy and its Geopolitical Strategy. Shanghai: Shanghai People's Publishing House.

Cederman L E, 2002. Endogenizing geopolitical boundaries with agent-based modeling. Proceedings of the National Academy, 99(Suppl. 3): 7796-7303.

Chen S H, 2009. On the geopolitics and geoeconomics in the game between countries. Wuhan University of Technology (Social Science Edition), 22(3): 36-40. (in Chinese)

Clauset A, Gleditsch K S, 2012. The developmental dynamics of terrorist organizations. Plos One, 7(11): e48633. doi: 10.1371/journal.pone.0048633.

Cohen S B, 2014. Geopolitics: The Geography of International Relations. Shanghai: Shanghai Academy of Social Sciences Press.

Cotet A M, Tsui K K, 2013. Oil and conflict: What does the cross country evidence really show? American Economic Journal: Macroeconomics, 5(1): 49-80.

Daras N J, Mazis J T, 2015. Systemic geopolitical modeling. Part 1: Prediction of geopolitical events. GeoJournal, 80(5): 653-678.

Desmet K, Breton M L, Ortuño-Ortín I et al., 2011. The stability and breakup of nations: A quantitative analysis. Journal of Economy Growth, 16(3): 183-213.

Ding F Y, Ge Q S, Jiang D et al., 2017. Understanding the dynamics of terrorism events with multiple-discipline datasets and machine learning approach. Plos One, 12(6): e0179057.

Erickson A S, Goldstein L J, Li N, 2014. China, the United States, and 21st Century Sea Power. Beijing: China Ocean Press.

Evans G, Newnham J, 1998. The Penguin Dictionary of International Relations. London: Penguin Books Press.

Fernández-Delgado M, Cernadas E, Barro S et al., 2014. Do we need hundreds of classifiers to solve real world classification problems? Journal of Machine Learning Research, 15(1): 3133-3181.

Funke M, Schularik M, Trebesch C, 2015. Going to extremes: Politics after financial crisis, 1870-2014. CESifo Working paper No.5553. (accessed November, 2017 http://hdl.handle.net/10419/123202).

Future Earth, 2017. Research for global sustainability. (accessed November, 2017 http://www.futureearth.org/).

Gao P, Guo D S, Liao K et al., 2013. Early detection of terrorism outbreaks using prospective space-time scan statistics. The Professional Geographer, 65(4): 676-691.

Ge Quansheng, Jiang Dong, Lu Feng et al., 2017. Views on the study of geopolitical environment system simulation. Acta Geographica Sinica, 72(3): 371-381. (in Chinese)

Ge Quansheng, Wang Fang, Chen Panqin et al., 2007. Review on global change research. Advances in Earth Science, 22(4): 417-427. (in Chinese)

GEA, 2012. Global Energy Assessment: Toward a Sustainable Future. Cambridge, UK and New York, NY, USA: Cambridge University Press, and the International Institute for Applied Systems Analysis, Laxenburg, Austria.

Hirsch M W, Smale S, Devaney R L, 2008. Different Equation, Dynamical System and an Introduction to Chaos. Beijing: Posts and Telecom Press.

Hsiang S M, Burke M, Miguel E, 2013. Quantifying the Influence of Climate on Human Conflict. Science, 341(6151): 1212.

Jasny B R, Stone R, 2017. Prediction and its limits. Science, 355(6324): 468-469.

Joshua K, 2012. A basic model explaining terrorist group organizational structure. Studies in Conflict \& Terrorism, 35(11): 810-830.

Kennedy R, Wojcik S, Lazer D, 2017. Improving election prediction internationally. Science, 355(6324): 515-520.

Kim H M, 2010. Comparing measures of national power. International Political Science Review, 31(4): $405-427$.

Kiruthiga A, Bose S, Buvaneswari N, 2015. An experimental simulation of hub-spoke terrorist organizational structure. Advances in Natural and Applied Sciences, 9(9): 41-44.

Kissinger H, 2012. Big Diplomacy. Hainan: Hainan Press.

Kong X H, 2010. Analyze on ways of geopolitics affecting a state's security strategy. World Regional Studies, 
19(2): 19-26. (in Chinese)

Lu Dadao, Du Debin, 2013. Some thoughts on the strengthening of geopolitical and geoeconomic studies. Acta Geographica Sinica, 68(6): 723-727. (in Chinese)

Mackinder H J, 1904. The geographical pivot of history. Geographical Journal, 23(4): 421-437.

Mahan A T, 2006. The Influence of Sea Power upon History. Beijing: The People's Liberation Army Press.

Mao H Y, 2013. Geopolitical and geoeconomic situation in the surrounding areas and China's strategies. Progress in Geography, 33(3): 289-302. (in Chinese)

Ma X, Fox P, Tilmes C et al., 2014. Capturing and presenting provenance of global change information. Nature Climate Change, 4(6): 409-413.

Mayer-Schonberger V, Cukier K, 2013. Big Data: A Revolution That Will Transform How We Live, Work, and Think. Eamon Dolan / Houghton Mifflin Harcourt.

Mazis I T, 2014. Methodology for systemic geopolitical analysis according to the Lakatosian model [D]. Turkey: Istanbul University.

Miller E, 2016. Patterns of Islamic State-related Terrorism, 2002-2015. START Background Report.

Muñoz B, García-Verdugo J, San-Martín E, 2015. Quantifying the geopolitical dimension of energy risks: A tool for energy modeling and planning. Energy, 82: 479-500.

Noguera-Santaella J, 2016. Geopolitics and the oil price. Economic Modeling, 52: 301-309.

Painter J, 1995. Politics, Geography and 'Political Geography': A Critical Perspective. London: Arnold Press.

Qin D H, 2014. Climate change science and sustainable development. Progress in Geography, 33(7): 874-883. (in Chinese)

Schneider G, Troeger V E, 2011. War and the world economy: Stock market reactions to international conflicts. Journal of Peace Research, 48: 481-495.

Seversky A D, 1950. Air Power: Key to Survial. New York: Simon and Schuster Press.

Spykman N J, 1965. The Geography of the Peace. Beijing: The Commercial Press.

UNEP GEO, 2017. Keeping the global environment under review. (accessed November, 2017 http://www. nep.org/geo/).

Von U N, Croicu M, Fjelde H et al., 2016. Civil conflict sensitivity to growing-season drought. Proceedings of the National Academy, 113(44): 12391-12396.

Weidmann N B, Girardin L, 2006. GROWLab: A Toolbox for Social Simulation, https://icr.ethz.ch/research/ rowlab/publications/.

White G, Porter M D, Mazerolle L, 2013. Terrorism risk, resilience and volatility: A comparison of terrorism patterns in three Southeast Asian countries. Journal of Quantitative Criminology, 29(2): 295-320.

World Economic Forum (WEF), 2017. The Global Risks Report 2017. (accessed November, 2017 http://wef.ch/ isks2017).

Xin W, 2016. China highly evaluates Russia's new national security strategy and positive statement on Sino-Russian relations. (accessed November, 2017. http://news.jxnews.com.cn/system/2016/01/04/ 014590917. shtml.

Zheng D, Chen S P, 2001. Progress and disciplinary frontiers of geographical research. Advance in Earth Sciences, 16(5): 599-605. (in Chinese) 